\title{
Quality of Space in Cities Respecting Requirements of Specific Target Groups as Objective of Smart City Concepts
}

\author{
Dagmar Petrikova ${ }^{1}$, Silvia Ondrejickova ${ }^{2}$ \\ \{dagmar_petrikova@stuba.sk ${ }^{1}$, silvia.ondrejickova@stuba.sk²
}

Institute of Management, Slovak University of Technology in Bratislava, Vazovova 5, 81243

Bratislava, Slovakia ${ }^{1}$, Spectra Centre of Excellence, Slovak University of Technology in Bratislava,

Vazovova 5, 81243 Bratislava, Slovakia ${ }^{2}$

\begin{abstract}
Perception of smart city concept from the point of view of the quality of space in cities has been analysed in relation to specific target groups within urban population. There are the needs of specific target groups that have to be taken into account in the concept of smart city. To the specific target groups belong mainly children and young people (including persons accompanying them), senior people, persons with physical disabilities, persons with sensual disabilities (blind and partially sighted, deaf), persons with mental disabilities. Their specific needs have been analysed primarily from the point of view of urban safety, mobility in public space and social activities. This paper is based on research findings, expert evaluations and social study carried out in 2012 and 2013 in the city of Trenčín under the "Security as a Quality Area", and follow-up projects in cooperation with the City of Trenčín in Slovakia.
\end{abstract}

Keywords: smart city, spatial quality, risks, perception of safety, specific groups of urban population

\section{Introduction}

Current perception of smart city concepts is mainly through the issue of technology and tools that have been built and implemented into everyday city life. However, the current challenges the contemporary modern cities face, follow from the increasing instability of environment (climate change, social change, economic shocks), in which the local governments have to manage the cities [1]. The common element of a range of possible approaches to smart city, whether in the form of direct or indirect objectives, is the quality of life for people living in these cities. This leads to the core target group of smart city concepts that are urban residents.

This group, however, is not characterized by a consistent set of individuals, but consists of the diversity of the individuals and groups with different requirements for the "quality" of the city. The common denominator of these groups are the requirements for the final quality of city space - reflecting the full range of applied innovations in the city. One of the basic requirements for 
individual space quality is the space safety, whatever the perceived safety as an objective or subjective value-quality space means. [1].

Changes in the value systems cause a shift in the views of the human beings/users of space as a primary reference unit for assessing the safety of the environment. Renaissance model of excellence and referenced individual La Vitruvian Man defined and illustrated by Leonardo da Vinci, drawing on the principles of "de Architectura Libri X 'incurred in Roman times, defines man as a perfect work of God, including the proportions of the body that were transferred into object model of architecture. The onset of the functionalist period, Le Corbusier [2] defined as a model for the creation of an environment in the context of urban planning "Le Modulor" , so called the average person. At present there is an appreciable shift in the perception of an exemplary universal human subject, defined by the principle of "design for all". However, even this concept is insufficient and there is a significant need to shift the perception in favour of the "most vulnerable" individual as the unit of reference, and any environment should be adapted to suit his/her needs, including requirements for safety - which at the same time can also achieve meeting the needs of everyone else. In addition, a much greater extent takes into account the individual needs of each individual subject not only with regard to the physical and psychological predispositions, but also to social and cultural dimensions.

Safety is a broad area that is difficult to define by the exact boundaries - we can find just as many areas of security, as many different risks and potential threats in the environment exist, even in the cases if its width is restricted to the referenced safety with respect to human beings. Thus, the purpose of this article is to define the requirements of "the most vulnerable" individuals, i.e. "specific" groups in the area, as important target area qualities for smart city concepts and innovations they bring in. [3]

This paper is based on research findings, expert evaluations and social study carried out in 2012 and 2013 in the city of Trenčín under the "Security as a Quality Area", and follow-up projects in cooperation with the City of Trenčín, the District Authority in the Region of Trenčín and the Regional Directorate of the IRS of 112.

\section{Urban safety}

When defining safety in an urban environment - the urban safety in Slovakia encounters a fundamental problem of a lack of theoretical basis aimed at urban safety. The current legislation recognizes the concept of safety and security in terms of various levels and issues, whether it is health and safety at work, role and mission of the Police Force and other security and rescue forces in Slovakia, or the Criminal Law, but in any legal norm is not even marginally addressed the issue of urban safety.

General definition of the meaning of "safety" no longer sufficient if we talk about "urban safety" - here we have to add, literally and in a figurative sense, the term "urban dimension". The urban safety encompasses a broad range of issues and activities tied primarily on publicly accessible spaces from (preventing) crime over the safety of the physical environment, 
accessibility (barrier-free accessibility and design principles for all - "universal design") to institutional and organizational aspects. Therefore, it is possible to define urban safety as "human safety within built-up areas (urban) of the city, especially in public areas. It relates to any kind of human safety in relation to the phenomena and activities in these public areas "[2].

\section{Specific groups and their requirements for quality of space}

Communities are considerably internally diversified, encompassing the various social groups with their specific lifestyle needs, interests, attitudes and abilities. These include groups that are compared to other groups much more sensitive to the state and conditions of the area, in particular to the public area. It is possible to define 5 basic specific population groups:

- Children and young people (including persons accompanying them);

- Seniors;

- Persons with physical disabilities;

- Persons with sensual disabilities (blind and partially sighted, deaf);

- Persons with mental disabilities.

The composition of these groups is dynamic, as well as their presence in different types of areas. In terms of duration the attachment to a particular group can be associated with specific momentary temporary disposition (e.g. short-term illness), stage of life (e.g. children), but also long-term disposition (e.g. congenital disability). In terms of time of their occurrence in a particular area their presence can be random, regularly recurring or permanent. This assessment, however, needs to be done in the dimension of the whole community of a particular area. Consequently, although from the perspective of an individual it can be a unique situation, the presence of these groups in public areas should be characterized as a permanent phenomenon. In the following part there are defined the significant quality requirements for each area from the point of view of specific groups as the base target qualities of the area for smart city concepts and innovations they bring in.

\subsection{Requirements of the children for the quality of space}

Children and youth, regardless of their age definition, or other parameters are one of the most vulnerable social groups in an urban environment.

- Orientation in space: For a dense, opaque, or inarticulate (monotonous) built area the child has a problem of orientation in space, identifying his/her home, identifying with their environment. It is therefore necessary to provide the area for children with basic orientation retaining elements (points, buildings and sites) in combination with a strong symbolic colour differentiation, using both iconic and symbolic and index features.

- Mobility and movement in space: An important aspect of safety for this specific group is the physical security of their movement in the environment. The basic key to its increase is the horizontal and vertical segregation (separation) of pedestrian movement and functional space activities for children from the car and other motorized transport, but also from intense cycling.

- Accessibility, physical structures and surfaces: The important aspect of the safety of children is also optimizing communications for their movement through the selection of a suitable 
surface, glass, color differentiation or other clear definition of removing dangerous obstacles to movements and obstacles to movement of parents with stroller (width parameters of communication, crossing the roads and the like.)

- It should also focus on the quality associated with the interaction of a child with physical and social environment of public space in particular in the context of the child claims on the hygienic quality (possibility of infections and contamination of environment), social quality (contact with socio-pathological phenomena such as drug dealing, sexual deviance, blackmail and bullying, etc.), environmental quality (presence of pollutants, carcinogens and poisons, allergens, toxic plants, especially with colored fruits) and other risks associated with reduced mental and physical abilities of the child (e.g. the danger of drowning, suffocation by small objects, falling from a height, play with fire, explosives, etc.).

\subsection{Requirements of the seniors for the quality of space}

In post-productive age level of mental and physical ability decreases depending on the lifestyle and health, passed illnesses in life, and these may become serious obstacles to the smooth use of public space in settlements.

- Orientation in space: Just as with the group of children also for the seniors is optimal readable built-up area with clear orientation points in a conspicuous place within a reasonable sufficient height. It is advisable not only to supplement the differentiation of individual area but also to use the indicative elements such as color depth markings, promote articulation diversifying environment (diversity) with greening and so on.

- Identification with space and social interaction: Breakdown of public spaces in the hierarchy of public and semi-public spaces allows creation of personal ties to the partial spaces, identification of the elderly with these spaces, creates space to develop stable social contacts and intergenerational interaction, easy navigation and social control. In terms of perceived safety it is very important to enable seniors to take part in the active participation in the codesign of public spaces in order to formulate specific requirements for their quality.

- Accessibility, physical structures and surfaces: For the safe movement of seniors with limited mobility and susceptibility to injuries with serious consequences for independent movement there is an essential element of the flawless surface roads, particularly pavements with no signs of degradation. In case of bad weather conditions, it is important not to use the materials for surface treatment, which in contact with water, snow, leaves are slippery, respectively it is necessary to adapt and create convex or concave relief.

- Green and relevant infrastructure: The path of mobility for seniors in public areas is necessary to provide with opportunities to stop and rest, for example construction of platforms. They need to be properly provided with overshadow tree greenery, fitted with appropriate sanitation.

- Transparency facilities: Public spaces, areas around residential buildings and roads for pedestrians must be adequately lit and with an emphasis on reducing the risk of the elderly as victims of crime. For safety, it is appropriate to ensure good visibility entering the house, the premises where the waste containers are placed etc. 
- Mobility: It is appropriate to equip pedestrian crossings on busy roads by traffic lights for pedestrians so that the seniors have the opportunity to pass safely. Limited speed of seniors in combination with impaired ability to perceive and respond to dynamically changing traffic situations are the key risk for seniors when moving in the communication space of the city.

- Functional structure of space and availability: The optimum is that the goals of the movement of the elderly, such as shops for basic foodstuffs, service facilities and specific social service offices, health centers, pharmacies, etc. are within the city concentrated in well accessible local centers without the need for transportation over long distances, eventually served by public transport available to the handicapped stops and vehicles. In terms of functions in residential areas (depending on the type of buildings) it is optimal if there is an area with social and relaxing features, in direct relation to the residential buildings, such as park space, where they can spend time together on the basis of neighborhood communication, building specific relationships and thus create a functioning community.

- Communities: As part of a functioning community in the event of bad physical situation of a senior person and the need of help it creates a sense of security in the form of neighborhood assistance, rapid response to emerging security risk (e.g. fire, vandalism, robbery) appropriate measures, such as calling emergency medical services, firemen, police and the like.

\subsection{Requirements of persons with disabilities for the quality of space}

This category includes persons with various forms of physical as well as mental disability in the whole range.

Persons with physical disabilities:

- Accessibility: When creating a public space, it is necessary to keep the parameters of the minimum dimensions and the slope of roads to allow wheelchair users to go through, to set up ramps at staircases, eventually lifts and elevators.

- Mobility: Creating parking spaces special dimensions in adequate number to the number of other parking spaces with adequate barrier-free traceable/ interconnectedness to key mobility targets (authorities, organizations providing services for this specific group, etc.).

Persons with sensual disabilities (blind and partially sighted, deaf)

- Light conditions in space: For people with visual impairments at intense sunlight may occur, for example the unrecognized contours of objects for people suffering from photophobia visual information is at intense sunlight unusable, while inadequate lighting has an absolute impact on the quality of vision of people suffering from night blindness. For this reason, the location and selection of the type of lighting for optimal shielding of buildings and other physical elements, the design and implementation of measures regulating brightness in public areas is essential.

- The physical structure used materials and maintenance: Leaves, snow, a lot of water from precipitation on roads and overgrown untreated lawns and shrubs in public areas, which overlap the elements used for orientation (interface of lawns and sidewalks, roads, embossed tiles) and change their functionality and often cause difficulties in mobility and orientation of sighted persons. 
- Communication protocols and social control: Sensually impaired people lose their perception of verbal and nonverbal expression of other persons who may suspect their bad faith. In the work of the security forces the description of the perpetrator is usually a problem, in case the victim of a crime is visually and mentally handicapped person. In this situation it is appropriate to introduce a procedure where the eyewitness testimony of witnesses is requested which would provide even a description of the perpetrator, in case the victim of a crime is visually and mentally handicapped person. For deaf people it is appropriate to use sign language interpreters.

- Communication, signalling and warning: Depending on the degree of hearing impairment, a greater proportion of these people at least recognize the overtones, e.g. warning sirens. In the interior this can be replaced by audio information through assistive devices responsive to light signal noise and vibration, which is in the public space more difficult, but not impossible. In a situation of public emergency it is the opportunity to inform deaf by telephone with light signals and sending text messages.

- Orientation and elements supporting it: In the dimension of micro-environments, it is important to think of a site approach by the sense of touch and of the safety of visually impaired persons in the process of tactile perception, e.g. removal of sharp edges, cover parts that threaten their movement, temperature, surface chemistries and the like. The dimension of macro-space is rather about creating a vision, mental maps, which then can be applied as a basis for the visually impaired orientation in space. As a guide to familiarize yourself with that space (especially with public spaces) or more objects it is appropriate to use three-dimensional models, for example. install a relief map, scale models of historic buildings, etc.

- Functional structure: When moving in public areas there is a problem, respectively there is a risk for visually impaired persons if there is a change in their functions, e.g. the location of physical and functional elements (pedestrian crossing was moved to a different location) has been changed. Since the foundation of their orientation in space is a mental model based on sharing experiences or based on previous interactions with space, any variation in the reality space of the model represents a loss in the ability of the visually impaired persons to get oriented in this space. Therefore it is necessary to clearly indicate these changes and provide information on the change, not only in the form of text, as any written information about the change or danger is irrelevant for visually impaired persons, (e.g. subway is closed, go to the other side and so on).

Persons with mental disabilities.

- Orientation, communication: One of the methods used in the education of mentally disabled individuals is "social reading" that can be categorized as unconventional form and understood as recognition, interpretation and appropriate responses to visual signs and symbols, pictograms, which appear in surrounding environment.

\section{Discussion}

This approach creates space for the acceptance of specific groups as reference group of the smart city concepts in terms of the implementation of their activities in a local community area to which the concept is applied. Quality and safe environment is one of the key aspects of smart city leading to the final goal, which is the quality of life and urban sustainability for population. At the same time including the needs of specific social groups for safe 
environment to be able to achieve active social life shifts the concept of smart city much closer to the city smart for all citizens.

\section{Acknowledgements}

This contribution is the result of the project implementation: SPECTRA+ No. 26240120002

"Centre of Excellence for the Development of Settlement Infrastructure of Knowledge Economy" supported by the Research \& Development Operational Programme funded by the ERDF.

\section{References}

[1] Ondrejičková, S., Ondrejička, V. (2013) Urban safety as a precondition for the quality of space. Urbanizmus a územní rozvoja (16): p.24-28

[2] Sert, J., L. (1973) Le Courbusier - The Athens Charter. New York : Grossman Publishers

[3] Finka, M., Ondrejička, V., Jamečný, L., et al. (2012) Bezpečnost' ako kvalita priestoru - úvod do problematiky. Centrum urbánnej bezpečnosti/ROAD. Bratislava

[4] Corbusier, Le. (2000) Le Modulor and Modulor 2. Birkhäuser Architecture; 1 edition. ISBN 9783764361884

[5] Zhang, H., Dai, Shenzhi., (2005) Literature review of safety research in urban planning. Urban Planning Forum. p. 007. ISSN 1000-3363.

[6] Colquhoun, I. (2004) Design Out Crime. Creating safe and Sustainable Communities. Oxford: Architectural press: p. 186

[7] Finka, M., Ondrejička, V. (2014) Urban safety in the context of integrated urban development. In: 13th International conference Ochrana obyvatel'stva 2014. pp. 23-26. VŠT Ostrava 